\title{
The Mysteries of Streptococcal Pharyngitis
}

\section{Judith M. Martin, M.D.}

\author{
Address \\ Division of General Academic Pediatrics, Children's Hospital of Pittsburgh, \\ University of Pittsburgh School of Medicine, 3414 Fifth Ave. 3rd Floor CHOB, \\ Pittsburgh, PA 15213, USA \\ Email: judy.martin@chp.edu
}

Published online: 7 April 2015

(C) Springer International Publishing AG 2015

This article is part of the Topical Collection on General Pediatrics

Keywords Streptococcus pyogenes - Pharyngitis - Group A Streptococcus - Carrier

\section{Opinion statement}

Streptococcal pharyngitis is common in children between 5 and 15 years of age. While there is a "classic" presentation, few patients have all of the characteristic signs and symptoms. Therefore, for those children who present with a sore throat in the absence of other respiratory symptoms such as nasal congestion and cough, the best method of determining the etiology of the illness is to obtain a swab of the tonsils and posterior pharynx and to test it for the presence of Group A Streptococci (GAS). Performing this testing, allows the clinician to safely avoid the use of antibiotics in children who do not test positive for this pathogen. These children are more likely to have a viral cause for their illness. Conversely, those who test positive for GAS can be offered antibiotics, such as penicillin or amoxicillin for treatment. Administering antimicrobial therapy will lead to more rapid clinical improvement and will decrease person to person transmission. In addition, it will prevent suppurative and some non-suppurative complications such as rheumatic fever. Some patients will have multiple episodes of illness during one school year associated with a positive test for GAS. This either represents true recurrent GAS infections or recurrent viral illnesses in children who have become streptococcal carriers. There are strategies to assist with the clinical management of both of these groups of children.

\section{Introduction}

\section{Group A streptococcus}

Group A Streptococci (GAS) or Streptococcus pyogenes are Gram-positive bacteria that can be classified by their M proteins into emm types. Although GAS is most well known as a pathogen that can cause pharyngitis, it can also colonize the pharynx and skin without causing disease. Other infections due to $S$. pyogenes include skin and soft tissue infections such as cellulitis, pyoderma, and necrotizing fasciitis. A patient may also become bacteremic with GAS, and this can lead to the development of bone and joint infections. Suppurative complications that can arise immediately after an infection due 
to this bacterium include the development of a retropharyngeal abscess. Non-suppurative complications occur several weeks after an infection and include acute rheumatic fever and post streptococcal glomerular nephritis. This article will provide an overview of the clinical presentation and management of streptococcal pharyngitis, as well as discuss some of the mysteries of streptococcal pharyngitis.

\section{GAS pharyngitis}

The most common clinical manifestation of GAS infection is pharyngitis. A number of bacterial and viral pathogens can lead to inflammation of the pharynx. The majority of episodes of pharyngitis are caused by viral infections which cannot be treated with an antibiotic; however, it is important to determine if $S$. pyogenes is the bacteria causing the pharyngitis since antibiotic therapy can be provided. Failure to appropriately treat GAS may lead to complications. GAS pharyngitis is most common in school-aged children and is often diagnosed in late winter and early spring. During winter, approximately 15-25\% of all cases of pharyngitis in children will be caused by a streptococcal infection [1-3]. Elementary school children may develop one to three new streptococcal infections each school year [4].

\section{Case presentation}

- A mother brings her 9-year-old daughter to the pediatric clinic. She is a previously healthy young girl who awoke today with a sore throat and headache. She has no rash or other symptoms. She has a temperature of 100.1 degrees Fahrenheit measured orally, her heart rate is 84 beats per minute and her respiratory rate is 18 breaths per minute. On physical examination, she has no skin findings, she has tender anterior cervical adenopathy without overlying erythema or warmth, her throat is erythematous, and her tonsils are $2+$ in size with an overlying white exudate. The remainder of her examination is within normal limits. You inform this child and her mother that you would like to obtain a throat culture to assess for the presence of GAS. The child starts to cry and her mother asks if this is really necessary. She informs you that she has three other children and she knows that this is strep throat. She states the following: "This is the way their breath always smells when they have strep throat."
GAS pharyngitis commonly presents with the sudden onset of sore throat. It is often associated with headache, fever, and occasionally abdominal pain. This is different from the symptoms of a typical viral pharyngitis when the sore throat is accompanied by other respiratory symptoms such as cough, nasal congestion, and rhinorrhea. With streptococcal pharyngitis, the tonsils and pharynx may appear erythematous and an exudate is seen in $25 \%$ of cases. Approximately, half of the children with GAS will also have enlarged anterior cervical lymph nodes which may be tender. The history and physical examination cannot differentiate between pharyngitis due to GAS versus an illness due to other causes. GAS should be suspected when the patient has typical clinical symptoms and signs of inflammation on examination of the pharynx; however, very few patients have all of the classic features [5]. Although a number of studies have shown that utilizing a clinical scoring system may be useful to help to predict which patients have GAS, laboratory confirmation is in the only method of making an accurate diagnosis [5-9]. Clinicians often overestimate the likelihood that GAS is the cause of pharyngitis and even mothers cannot make a diagnosis based on the smell of the breath.

\section{Making the diagnosis}

Since it is difficult to make a distinction purely based on symptoms and the clinical examination between viruses and GAS as a cause of pharyngitis, it is necessary to obtain a specimen by swabbing the surface of the tonsils and posterior pharynx and to test it with a rapid antigen detection test (RADT) or to send the swab to a laboratory for the performance of a bacterial throat culture. The gold standard testing method is considered to be the throat culture. The RADTs are based on extraction of the group A carbohydrate antigen from the cell wall of the bacteria and then identification using an immunoassay. These tests have a high specificity $>95 \%$. However, the sensitivity is variable depending on which method is used. Therefore, if a patient has a negative RADT, it is recommended that a throat culture should be performed to assess for GAS $[10 \bullet, 11 \bullet, 12]$.

Another reason that testing is recommended is because antibiotic treatment can be prescribed if the cause of the pharyngitis is determined to be GAS. There is a more immediate improvement of symptoms in patients who are prescribed antibiotics $[13,14]$. Treatment also reduces the rate of suppurative and some non suppurative complications and decreases person to person transmission. Performing this testing also allows us to safely 
avoid the use of antibiotics in patients who do not have GAS as the cause of their pharyngitis $[10 \bullet, 11 \bullet, 12]$.

\section{To test or not to test}

Obtaining a throat swab for testing for the presence of GAS is most useful when the pretest likelihood is high that the child's illness is streptococcal pharyngitis. Clinical presentations, which include nasal congestion, cough, hoarseness, or oral ulcers, are more suggestive of a viral etiology for the illness. For these children, GAS is not likely the cause of the symptoms and antibiotic treatment is not necessary. Testing is also not routinely recommended after a course of treatment is completed or in asymptomatic household contacts of children with streptococcal pharyngitis $[10 \bullet, 11 \bullet]$. Finally, with some exceptions, testing is not recommended in children $<3$ years old because the incidence of rheumatic fever is extremely low [11•]. In each of these situations, if the patient has a positive RADT or throat culture, it is probable that the child is a streptococcal carrier rather than acutely infected. GAS colonization rates can be as high as $25 \%$ in school age children in the winter [4]. Unnecessarily testing children unlikely to have true GAS infection can lead to overuse of antibiotics.

\section{Treatment}

\section{Treatment tips and tricks}

Treatment for streptococcal pharyngitis should be provided for children with symptoms that are compatible and who test positive for this pathogen. They should be treated with an antibiotic that has activity against GAS. The original clinical studies investigating the prevention of rheumatic fever used intramuscular penicillin [15]. Numerous other studies since then have been conducted with a variety of antibiotics. It has been presumed that a course of antibiotics which effectively eradicates the pathogen from the pharynx would also prevent the complication of rheumatic fever [11•].

It has been fortunate that while some Streptococcal species such as Streptococcus pneumoniae have developed resistance over time and require higher concentrations of penicillin to inhibit bacterial growth, $S$. pyogenes isolates have remained susceptible to penicillin [16-18]. In general, when treating a bacterial infection, it is preferable to use the most narrow spectrum antibiotic that will treat the infection. Penicillin is a narrow spectrum antibiotic which is an attractive option since it is well tolerated, has a low incidence of side effects, is inexpensive, and has proven efficacy in treating streptococcal pharyngitis. Amoxicillin, is also a narrow spectrum antibiotic, is often substituted for penicillin for younger children who prefer a more pleasant tasting liquid suspension. This is the current treatment recommendation from several groups including the following: the Infectious Disease Society of America, the American Academy of Pediatrics Committee on Infectious Disease, and the American Heart Association [10•, 11•, 12].

\section{Dosing tip}

Make it easy on yourself. Don't pull out your calculator to determine what dose to prescribe. It takes very little penicillin to treat streptococcal pharyngitis, and penicillin has a large therapeutic index and therefore there is very little toxicity with higher doses. I try to keep things simple. I only use two doses for the treatment of children with GAS pharyngitis. If the patient is less than 27 kilograms (kg), (60 lbs) I prescribe penicillin or amoxicillin $250 \mathrm{mg}(\mathrm{mg})$ twice a day for a duration of 10 days. If the child is greater than $27 \mathrm{~kg}$ (60 lbs), I 
prescribe $500 \mathrm{mg}$ twice a day for 10 days duration. There is recent data to support once a day dosing of amoxicillin, and it has been recommended by the American Academy of Pediatrics Committee on Infectious Diseases as well as by the 2009 American Heart Association guidelines [10•, 12, 19, 20]. However, it is not approved by the Food and Drug Administration for children younger than 12 years of age. The bottom line-if it is easier for the family to administer amoxicillin once per day, then use $50 \mathrm{mg} / \mathrm{kg}$ (maximum dose of $1000 \mathrm{mg}$ ). This should only be prescribed if you are comfortable that the family will be adherent to a schedule of once a day dosing (see Table 1).

\section{What if the child is so sick that they cannot tolerate any oral medications?}

The best alternative if the child is quite ill and cannot tolerate swallowing an oral medication or when it is anticipated that it will be a struggle to administer a daily antibiotic for 5 to 10 days, then the clinician should consider using benzathine penicillin $\mathrm{G}$. This can be given as a one-time intramuscular dose. It will be slowly absorbed over time and will provide sufficient serum levels of antibiotic and effective therapy to treat streptococcal pharyngitis and to prevent rheumatic fever [15].

\section{What if my patient is allergic to penicillin or amoxicillin?}

For children who are allergic to amoxicillin or penicillin, who did not have anaphylaxis to these medications, a first-generation cephalosporin such as cephalexin can be prescribed. Numerous studies have shown the effectiveness of oral cephalosporins for the treatment of GAS pharyngitis (see Table 1) [21, 22]. Some studies have reported higher bacteriologic cure rates with the cephalosporins compared to the penicillins [21-23]. Because of this, some clinicians prefer to prescribe cephalosporins. However, it is important to note that the differences in bacteriologic success rates in some studies may be due to the inclusion of children who were GAS carriers rather than acutely infected children. It is known that cephalosporins are more effective at eradicating the carrier state when compared to penicillin $[21,22]$. While there may be some

Table 1. Antibiotic dosages commonly used for treatment of streptococcal pharyngitis in children

\begin{tabular}{|c|c|c|}
\hline Medication & Dosage & Duration \\
\hline \multirow[t]{2}{*}{ Penicillin V, oral } & $<27 \mathrm{~kg}: 250 \mathrm{mg}$ BID & 10 days \\
\hline & $\geq 27 \mathrm{~kg}: 500 \mathrm{mg}$ BID & \\
\hline \multirow[t]{4}{*}{ Amoxicillin, oral } & $<27 \mathrm{~kg}: 250 \mathrm{mg}$ BID & 10 days \\
\hline & $\geq 27 \mathrm{~kg}: 500 \mathrm{mg}$ BID & \\
\hline & OR: $50 \mathrm{mg} / \mathrm{kg}$ QD (max.=1000 mg) & \\
\hline & OR: $25 \mathrm{mg} / \mathrm{kg}$ BID (max=500 mg) & \\
\hline \multirow[t]{2}{*}{ Benzathine penicillin G, IM } & $<27 \mathrm{~kg}: 600,000$ units & One dose \\
\hline & $\geq 27 \mathrm{~kg}: 1.2$ million units & \\
\hline Cephalexin, oral & $20 \mathrm{mg} / \mathrm{kg} /$ dose BID (max. $=500 \mathrm{mg} /$ dose) & 10 days \\
\hline Cefadroxil, oral & $30 \mathrm{mg} / \mathrm{kg} \mathrm{QD}(\max .=1000 \mathrm{mg})$ & 10 days \\
\hline Clindamycin, oral & $7-10 \mathrm{mg} / \mathrm{kg} /$ dose TID (max.=300 mg/dose) & 10 days \\
\hline Azithromycin, oral & $12 \mathrm{mg} / \mathrm{kg}$ QD $(\max .=500 \mathrm{mg})$ & 5 days \\
\hline Clarithromycin, oral & $7.5 \mathrm{mg} / \mathrm{kg} / \mathrm{dose}$ BID (max.=250 mg/dose) & 10 days \\
\hline
\end{tabular}


advantages to the cephalosporins, they are more expensive, have a broader spectrum of activity, and in general have greater side effects than penicillin [23].

\section{What about the macrolide antibiotics?}

For children who had a severe allergic reaction to amoxicillin or penicillin, a macrolide antibiotic can be used. Azithromycin is more commonly used than erythromycin due to the gastrointestinal side effects seen with erythromycin. The advantage of using azithromycin is that you can prescribe 5 days of therapy. This is due to the pharmacokinetics and pharmacodynamics of this medication that provide a longer therapeutic effect. However, the dose of azithromycin that is recommended for treatment of streptococcal pharyngitis in children is $12 \mathrm{mg} / \mathrm{kg}$ given once a day with a maximum dose of $500 \mathrm{mg}$ [24]. The commonly prescribed prepackaged azithromycin tablets contains $500 \mathrm{mg}$ as a single dose on day 1 , followed by $250 \mathrm{mg}$ once daily on days 2 through 5 . For a $20-\mathrm{kg}$ child (44 lbs), this is double what is needed for the first day of therapy and it is the appropriate dose for days 2 through 5 . Any child greater than $20 \mathrm{~kg}$, who is prescribed this dose pack, will not receive the recommended $12 \mathrm{mg} / \mathrm{kg}$ on days 2 through 5 . It is therefore my preference to use the suspension formulation for children less than $40 \mathrm{~kg}$ or to use $500 \mathrm{mg}$ given once a day for 5 days for children greater than $40 \mathrm{~kg}$.

Another important issue to remember when using the macrolide antibiotics is that there are several reports of communities who have observed high rates of macrolide-resistant organisms including GAS [25-27]. Recently, Logan et al. reported two children who presented with rheumatic fever, which was felt to be secondary to an infection with a macrolide-resistant isolate of GAS [28]. It is important to be aware of the resistance rates in your community.

Clindamycin is an alternative for treating GAS pharyngitis; it should be considered for the rare circumstance that a child is allergic to penicillin and it is known or suspected that the GAS is macrolide-resistant [29]. Clindamycin suspension is not pleasant tasting and is not well tolerated by younger children. Therefore, when prescribing this medication, I prefer to prescribe clindamycin capsules. The dose for treatment is $20-30 \mathrm{mg} / \mathrm{kg} /$ day divided in three doses (with a maximum dose of $300 \mathrm{mg}$ ). Dosage formulations of the capsules are as follows: 150 or $300 \mathrm{mg}$. For a child who cannot swallow capsules who is between 15 and $23 \mathrm{~kg}$, I usually prescribe the 150-mg capsules which can be opened and the medication mixed with a small amount of applesauce. The 300mg capsules can be used for children over $30 \mathrm{~kg}$.

\section{Approach to the child with multiple episodes of pharyngitis}

\section{Case presentation}

- Sam is a 7-year-old boy who is in the second grade at school. It is March and he comes into the office with a sore throat and lowgrade fever. He has no nasal congestion, cough, or rash. On examination, he has an erythematous pharynx and his tonsils are also erythematous and +2 in size without any exudate. He has anterior and posterior cervical adenopathy without overlying 
erythema and no skin findings. The remainder of his examination is within normal limits.

- Based on his history and physical examination, you decide to perform a streptococcal RADT and it is positive for GAS. His mother points out that this is his third episode of streptococcal pharyngitis this school year. You review his medical record and you note that he has had multiple visits for respiratory illnesses and had several RADTs performed. There were three tests which were positive for GAS. He was prescribed amoxicillin at an appropriate dose for all three episodes, and his mother states that he completed a 10-day course of therapy each time. His mother wants to know why he keeps getting strep throat.

First, it is important to establish if this child is more likely to be presenting with recurrent episodes of GAS pharyngitis or if he might be a GAS carrier. It is key to try to distinguish between the two because management of each is different. A positive RADT or culture for GAS at the time of acute pharyngitis does not prove that Sam has GAS pharyngitis. Proof of GAS pharyngitis would require following antibody titers, which is not practical in typical clinical care. Instead, it is essential to take a careful history of the symptoms that were present with each illness and to assess the child's clinical response to the antibiotic therapy prescribed. The child with true recurrent episodes is most likely to have classic symptoms with each illness.

Children with pharyngitis due to GAS typically respond promptly with initiation of antibiotic therapy [13]. In contrast, children with a viral illness whose throat cultures are positive for GAS, who are GAS carriers, are less likely to have rapid improvement of their symptoms. While these clues are helpful, the best way to distinguish these two possibilities is to obtain a throat culture after the patient has completed therapy, at a time that they are without any symptoms. The child with true recurrent infections will have negative testing for GAS while the child who is a GAS carrier will have a positive throat culture at a time when they are well (see Table 2).

\section{A patient with true recurrent episodes}

- Sam completes his 10 days of amoxicillin and returns to your office 1 week later. He is well and completely back to normal. You obtain a bacterial throat culture, and it is negative for GAS. You determine that he is most likely having recurrent episodes of streptococcal pharyngitis. Now what do you advise this family?

In my experience, there are many children who are unfortunate enough to have several episodes of pharyngitis in one school year, especially boys in first and second grade. However, it is uncommon for a child to have multiple years with true recurrent episodes [4]. It is likely that some immunity develops over time as children become older and in addition, improve their hand hygiene which decreases transmission. Some clinicians recommend tonsillectomy for recurrent episodes of pharyngitis. However, the Infectious Disease Society of America guidelines do not recommend tonsillectomy as a way to prevent further episodes [11 $\bullet$. This is supported by a study by Paradise et al. in which children 
Table 2. Helpful hints to distinguish a child with true recurrent episodes of streptococcal pharyngitis from the child who is a streptococcal carrier

True recurrent episodes

Illness with classic symptoms

Symptoms improve within $24-48 \mathrm{~h}$ after initiation antibiotic therapy

Throat culture or rapid antigen detection test is negative when the child is asymptomatic
Streptococcal carrier

Illness not classic, may include respiratory symptoms such as cough and nasal congestion

Symptoms do not appear to improve with antibiotic therapy; illness lasts longer than 5 days

Throat culture or rapid antigen detection test is positive when the child is asymptomatic

were randomized to tonsillectomy versus observation for recurrent episodes of pharyngitis. He reported that while the children who had surgery had fewer episodes of pharyngitis in the 2 years post surgery compared to the non-surgical group, that benefit did not last. Both groups had fewer episodes each subsequent year [30]. In addition, surgery is associated with certain risks. Therefore, I advise these families, that if we can get them through the remainder of the current school year, then they will likely do well over the summer, when streptococcal pharyngitis is infrequent. After that, the odds are that they will do well the subsequent school year.

For the unusual child who has multiple $[3,4]$ documented true recurrent episodes of streptococcal pharyngitis in whom the family is considering tonsillectomy, I discuss with them the risks and benefits of daily amoxicillin prophylaxis until the end of the school year (late May) to prevent another episode. While the use of continuous antibiotic prophylaxis in general should be discouraged, due to the potential side effects and the ability to promote the development of bacterial resistance, it may incur fewer risks than surgery.

\section{A patient who is a streptococcal carrier}

- Let's say that alternatively, Sam returns 1 week after completion of his 10-day course of antibiotic and his mother informs you that amoxicillin did not work very well. She reports that he remained ill for over a week. He is currently without any sore throat or respiratory symptoms. You obtain a bacterial throat culture, and it is positive for GAS. You determine that he is most likely a streptococcal carrier. Now what do you advise this family?

The positive culture for GAS at a time that the child is without symptoms likely indicates carriage of this organism in his pharynx. His recent illness was more likely to have been caused by a viral infection. Even without antibiotic treatment, fever and symptoms due to streptococcal pharyngitis will resolve quickly within several days of the onset of illness [14]. The persistence of symptoms beyond this time period is commonly observed in a child who has a viral infection who may be a carrier of GAS (and not an acute infection). It is difficult to know when he became a carrier. He may have had a true episode of streptococcal pharyngitis earlier in the year, and at some point, the GAS became one of the colonizing bacteria in his pharynx. 


\begin{tabular}{|c|c|c|c|}
\hline Route & Agent & Dosage & Duration \\
\hline Oral & Clindamycin & $20-30 \mathrm{mg} / \mathrm{kg} /$ day in 3 doses (max.=300 mg/dose) & 10 days \\
\hline Oral & Penicillin and Rifampin & $\begin{array}{l}\text { Pen } V 50 \mathrm{mg} / \mathrm{kg} / \text { day in } 4 \text { doses } \times 10 \text { days ( } \max .=2000 \mathrm{mg} / \\
\text { day) } \\
\text { Rifampin: } 20 \mathrm{mg} / \mathrm{kg} / \text { day in } 1 \text { dose for each of the last } 4 \text { days } \\
\text { of treatment (Max.=600 mg/day) }\end{array}$ & 10 days \\
\hline Oral & Amoxicillin-clavulanic acid & $\begin{array}{l}40 \mathrm{mg} \text { of amoxicillin } / \mathrm{kg} / \text { day in } 3 \text { doses (max. }=2000 \mathrm{mg} \\
\text { amoxicillin/day) }\end{array}$ & 10 days \\
\hline IM & $\begin{array}{l}\text { Benzathine penicillin G Plus } \\
\quad \text { Rifampin }\end{array}$ & $\begin{array}{l}600,000 \text { units for }<27 \mathrm{~kg} \\
1,200,000 \text { units for } \geq 27 \mathrm{~kg}\end{array}$ & 1 dose \\
\hline Oral & & $20 \mathrm{mg} / \mathrm{kg} /$ day in 2 doses $(\max .=600 \mathrm{mg} / \mathrm{d})$ & 4 days \\
\hline
\end{tabular}

Children who are streptococcal carriers are not considered to be contagious and the GAS are simply colonizing the pharynx and are not causing disease. There is no immune response to the presence of the bacteria. In addition, these children are believed to be at little or no risk for developing suppurative or nonsuppurative complications such as acute rheumatic fever [31].

The child who is a GAS carrier presents challenges in clinical management. Under most circumstances, antimicrobial therapy is not indicated for these children. However, the American Academy of Pediatrics Committee on Infectious Diseases suggests several situations when it may be advantageous to eradicate GAS colonization [10•]. These include when there is a family history of rheumatic fever, when the family is anxious or is considering surgery because of the GAS carriage, or when there are outbreaks of GAS pharyngitis [10 $\bullet$. A review of the literature suggests that certain antimicrobial agents are associated with a higher likelihood for successful eradication [29-32]. However, there are only two studies whose primary outcome was to determine efficacy in eliminating GAS carriage. A ten-day course of oral clindamycin was found to be effective with successful eradication in $85-90 \%$ of the children who were GAS carriers [29]. The second study demonstrated success with the combination of benzathine penicillin $\mathrm{G}$ and oral rifampin [32]. Common alternatives that are prescribed include a 10-day course of amoxicillin plus clavulanic acid, or a firstgeneration oral cephalosporin which can be prescribed for the child's subsequent episode of pharyngitis with a positive throat swab for GAS in hope to eradicate the GAS [33] (see Table 3).

\section{Conclusion}

In conclusion, streptococcal pharyngitis is very common in school-aged children. While there is a classic clinical presentation, it is difficult to distinguish based on clinical presentation alone, between pharyngitis due to GAS versus pharyngitis due to a virus. Therefore, testing is recommended to determine the etiology of the illness. While children will improve without any treatment, antibiotics will lead to a more rapid clinical improvement and will help to decrease transmission from person to person. Antibiotic treatment will also 
prevent suppurative and some non suppurative complications. Children with multiple episodes of pharyngitis during one respiratory season may be experiencing true recurrent infections or may be carriers of GAS with symptoms due to a viral illness. By taking a careful history and testing at a time when they are asymptomatic you may be able to solve the mystery.

\section{Compliance with Ethics Guidelines}

\section{Conflict of Interest}

Judith M. Martin declares that she has no conflicts of interest.

\section{Human and Animal Rights and Informed Consent}

This article does not contain any studies with human or animal subjects performed by any of the authors.

\section{References and Recommended Reading}

Papers of particular interest, published recently, have been

highlighted as:

- Of importance

1. White CB, Bass JW, Yamada SM. Rapid latex agglutination compared with the throat culture for the detection of group A streptococcal infection. Pediatr Infect Dis. 1986;5(2):208-12.

2. Tanz RR, Shulman ST. Pharyngitis. In: Long SS, Pickering LK, Prober CG, editors. Principles and practices of pediatric infectious diseases. New York: Churchill Livingstone; 1997. p. 200-7.

3. Pichichero ME, Disney FA, Green JL, Francis AB, Marsocci SM, Lynd AM, et al. Comparative reliability of clinical, culture, and antigen detection methods for the diagnosis of group A beta-hemolytic streptococcal tonsillopharyngitis. Pediatr Ann. 1992;21(12):798-805.

4. Martin JM, Green M, Barbadora KA, Wald ER. Group A streptococci among school-aged children: clinical characteristics and the carrier state. Pediatrics. 2004;114(5):1212-9.

5. Breese BB. A simple scorecard for the tentative diagnosis of streptococcal pharyngitis. Am J Dis Child. 1977;131(5):514-7.

6. Wald ER, Green MD, Schwartz B, Barbadora K. A streptococcal score card revisited. Pediatr Emerg Care. 1998;14(2):109-11.

7. Poses RM, Cebul RD, Collins M, Fager SS. The accuracy of experienced physicians' probability estimates for patients with sore throats. Implications for decision making. JAMA. 1985;254(7):925-9.

8. McIsaac WJ, Kellner JD, Aufricht P, Vanjaka A, Low DE. Empirical validation of guidelines for the management of pharyngitis in children and adults. JAMA. 2004;291(13):1587-95.
9. Shaikh N, Swaminathan N, Hooper EG. Accuracy and precision of the signs and symptoms of streptococcal pharyngitis in children: a systematic review. J Pediatr. 2012;160(3):487.

10. American Academy of Pediatrics. Group A Streptococcal Infections. Red book: report of the committee on infectious diseases, 29th edition. Elk Grove Village: American Academy of Pediatrics; 2012.

These are the most recent recommendations from the American Academy of Pediatrics Committee on Infectious Diseases. The Red Book is always a great source for pathogen specific information for diagnosis and treatment. There will be an update in May 2015.

11. Shulman ST, Bisno AL, Clegg HW, Gerber MA, Kaplan EL, Lee G, et al. Clinical practice guideline for the diagnosis and management of group A streptococcal pharyngitis: 2012 update by the Infectious Diseases Society of America. Clin Infect Dis. 2012;55(10):e86102.

These are the most recent recommendations from a committee of experts from the Infectious Disease Society of America. It is written in a question and answer format. The strength of each recommendation and the quality of evidence is graded.

12. Gerber MA, Baltimore RS, Eaton CB, Gewitz M, Rowley AH, Shulman ST, et al. Prevention of rheumatic fever and diagnosis and treatment of acute Streptococcal pharyngitis: a scientific statement from the American Heart Association Rheumatic Fever, Endocarditis, and Kawasaki Disease Committee of the Council on Cardiovascular Disease in the Young, the Interdisciplinary Council on Functional Genomics and Translational 
Biology, and the Interdisciplinary Council on Quality of Care and Outcomes Research: endorsed by the American Academy of Pediatrics. Circulation. 2009;119(11):1541.

13. Nelson JD. The effect of penicillin therapy on the symptoms and signs of streptococcal pharyngitis. Pediatr Infect Dis. 1984;3(1):10-3.

14. Brink W, Rammelkapm CJR, Demmu FW, Wannamaker L. Effect in penicillin and aureomycin on the natural course of streptococcal tonsillitis and pharyngitis. Am J Med. 1951;10(3):300-8.

15. Chamovitz R, Catanzaro FJ, Stetson CA, Rammelkamp $\mathrm{CH}$. Prevention of rheumatic fever by treatment of previous streptococcal infections. Evaluation of benzathine penicillin G. N Engl J Med. 1954;251:466.

16. Horn DL, Zabriskie JB, Austrian R, et al. Why have group A streptococci remained susceptible to penicillin? Report on a symposium. Clin Infect Dis. 1998;26:1341.

17. Kaplan EL, Johnson DR, Del Rosario MC, Horn DL. Susceptibility of group A beta-hemolytic streptococci to thirteen antibiotics: examination of 301 strains isolated in the United States between 1994 and 1997. Pediatr Infect Dis J. 1999; 18(12):1069-72.

18. Whitney CG, Farley MM, Hadler J, Harrison LH, Lexau $\mathrm{C}$, Reingold A, et al. Increasing prevalence of multidrug-resistant Streptococcus pneumoniae in the United States. N Engl J Med. 2000;343(26):1917.

19. Feder Jr HM, Gerber MA, Randolph MF, Stelmach PS, Kaplan EL. Once-daily therapy for streptococcal pharyngitis with amoxicillin. Pediatrics. 1999;103(1):47-51.

20. Clegg HW, Ryan AG, Dallas SD, Kaplan EL, Johnson DR, Norton HJ, et al. Treatment of streptococcal pharyngitis with once-daily compared with twice-daily amoxicillin: a noninferiority trial. Pediatr Infect Dis J. 2006;25(9):761.

21. Casey JR, Pichichero ME. Meta-analysis of cephalosporin versus penicillin treatment of group A streptococcal tonsillopharyngitis in children. Pediatrics. 2004;113(4):866-82.

22. Pichichero ME, Margolis PA. A comparison of cephalosporins and penicillins in the treatment of group A beta-hemolytic streptococcal pharyngitis: a metaanalysis supporting the concept of microbial copathogenicity. Pediatr Infect Dis J. 1991;10(4):27581.

23. Shulman ST, Gerber MA. So what's wrong with penicillin for strep throat? Pediatrics. 2004;113(6):1816-9.

24. Cohen R. Defining the optimum treatment regimen for azithromycin in acute tonsillopharyngitis. Pediatr Infect Dis J. 2004;23(2 Suppl):S129-34.

25. Martin JM, Green M, Barbadora KA, Wald ER. Erythromycin-resistant group A streptococci in schoolchildren in Pittsburgh. N Engl J Med. 2002;346(16):1200-6.

26. Green M, Martin JM, Barbadora KA, Beall B, Wald ER. Reemergence of macrolide resistance in pharyngeal isolates of group a streptococci in southwestern Pennsylvania. Antimicrob Agents Chemother. 2004;48(2):473-6.

27. Seppala H, Nissinen A, Jarvinen H, Huovinen S, Henriksson T, Herva E, et al. Resistance to erythromycin in group A streptococci. N Engl J Med. 1992;326(5):292-7.

28. Logan LK, McAuley JB, Shulman ST. Macrolide treatment failure in streptococcal pharyngitis resulting in acute rheumatic fever. Pediatrics. 2012;129(3):e798802.

29. Tanz RR, Poncher JR, Corydon KE, Kabat K, Yogev R, Shulman ST. Clindamycin treatment of chronic pharyngeal carriage of group A streptococci. J Pediatr. 1991;119(1):123-8.

30. Paradise JL, Bluestone CD, Bachman RZ, Colborn DK, Bernard BS, Taylor FH, et al. Efficacy of tonsillectomy for recurrent throat infection in severely affected children. Results of parallel randomized and nonrandomized clinical trials. N Engl J Med. 1984;310(11):674-83.

31. Kaplan EL. The group A streptococcal upper respiratory tract carrier state: an enigma. J Pediatr. 1980;97(3):337.

32. Tanz RR, Shulman ST, Barthel MJ, Willert C, Yogev R. Penicillin plus rifampin eradicates pharyngeal carriage of group A streptococci. J Pediatr. 1985;106(6):87680 .

33. Brook I. Failure of penicillin to eradicate group A betahemolytic streptococci tonsillitis: causes and management. J Otolaryngol. 2001;30(6):324-9. 